\title{
1. Responding to climate change: introduction and overview
}

\author{
Chin Hee Hahn, Sang-Hyop Lee, and \\ Kyoung-Soo Yoon
}

Climate change is becoming widely recognized as one of the most important changes in the world economic environment. Taking action to mitigate it has already become an inevitable task for policymakers. According to a forecast of the Organisation for Economic Co-operation and Development (OECD 2009), under the business-as-usual scenario and in the absence of new policy action, the atmospheric concentrations of the world's greenhouse gases (GHGs) will increase to about 650 parts per million (ppm) in 2050, which could cause the global average temperature to be at least $2^{\circ} \mathrm{C}$ higher than it was in preindustrial times. This in turn would impose a fundamental constraint on economic activities of mankind. Stern (2007) forecasts that the per capita loss from climate change could be about 14.4 percent of the world's average per capita income. Based on this recognition, the World Bank (2008) notes that climate change is one of the "new global trends" that could threaten the sustained growth of the world economy and in particular the growth of developing countries.

Climate change is regarded as a global trend, not only because of the threat it poses, but also because of the wide scope of its influence on economic activities. To mitigate and adapt to climate change, most countries will have to adopt new policy instruments, which may include a carbon tax, a cap-and-trade system, schemes to expand supplies of renewable energy, and tools for improving energy efficiency. In the course of implementing such policies, relative prices of goods and services will change, and markets related to climate change - the so-called green markets-will expand. Consumers will change their consumption patterns, and firms will have to adjust themselves to the new regulatory framework and new market situations. In the sense that economies should persistently improve, or reform, their systems of coping with internal and external environmental changes, as noted by Rodrik (2005), governments will 
have to take this trend into consideration in policies ranging widely from industry and the regulatory system to development strategy.

There are widespread uncertainties in the trend, however, and one critical source of uncertainty is the outcome of international cooperation and negotiations. Owing to the accumulative, nonassimilative nature of GHG, as well as its characteristic as a public good, international cooperation is essential in response to climate change. Since the 1990s, efforts to counter global warming have gradually intensified worldwide, leading to the adoption of the United Nations Framework Convention on Climate Change (UNFCCC) in 1992 and its enforcement in 1994, followed by the adoption of the Kyoto protocol in 1997 and its enforcement in 2005 for the period up to 2012. Ongoing negotiations to build a post-2012 global climate regime include the Bali Action Plan in 2007 and the Cancun Agreement in 2010, among others. They have, however, left a number of issues unresolved, especially between developed and developing countries. Although some issues were settled in the Cancun Agreement, which incorporates major decisions taken at the time of the 2009 Copenhagen Accord, critical issues such as a mitigation target remain to be solved.

Another critical uncertainty is the development of "green technology," which will affect mitigation costs. The costs, in turn, will affect decisions about whether to adopt a mitigation policy and what the policy design should be. Firms may delay, or even give up, investments in essential technologies if success and profitability seem doubtful. Public investment might be a solution, but any serious concern about policy failure might then create obstacles. This problem will probably be more critical in developing countries, in cases where technology is still at a lower level, although these countries could compete with developed ones in expanding green markets.

Facing the need for mitigation and the uncertainties surrounding it, the Korean government announced its Green Growth National Strategy in 2008, to be implemented according to the newly promulgated Framework Act on Low Carbon Green Growth. The purpose of this law is to harmonize the continued development of the national economy and enhancement of the quality of life, while at the same time fulfilling the nation's international responsibilities for protecting the environment. In other words, the strategy aims at forming a virtuous circular structure of economic development, improvement of the environment, and participation in international cooperation.

It seems appropriate for the Korean government to take the task of the response to climate change more seriously, leaving out the issue of whether green growth can be a national strategy. Foremost of all, the Korean peninsula itself is already experiencing the impact of climate change. 
Table $1.1 \mathrm{CO}_{2}$ emissions statistics for selected regions and countries, 2007

\begin{tabular}{lccccc}
\hline $\begin{array}{l}\text { Region or } \\
\text { country }\end{array}$ & $\begin{array}{c}\mathrm{CO}_{2} \\
\text { emissions } \\
\text { (million } \\
\text { tons) }\end{array}$ & $\begin{array}{c}\text { Rate of increase } \\
\text { (\%, annual } \\
\text { average } \\
1990-2007)\end{array}$ & $\begin{array}{c}\text { GDP } \\
\text { (US\$ billion } \\
\text { at 2000 } \\
\text { PPP) }\end{array}$ & $\begin{array}{c}\text { Emissions per } \\
\text { unit of GDP } \\
\text { (tons/US\$ } \\
\text { billion) }\end{array}$ & $\begin{array}{c}\text { Emissions } \\
\text { per capita } \\
\text { (tons) }\end{array}$ \\
\hline World & 28962.4 & 1.91 & 61428.0 & 0.47 & 4.38 \\
OECD & 13000.8 & 0.95 & 32360.9 & 0.40 & 10.97 \\
Annex I & 14259.1 & 0.15 & 32627.2 & 0.44 & 11.21 \\
United & 5769.3 & 1.01 & 11468.0 & 0.50 & 19.10 \\
$\quad$ States & & & & & \\
Japan & 1236.3 & 0.88 & 3620.2 & 0.34 & 9.68 \\
Canada & 572.9 & 1.67 & 1046.9 & 0.55 & 17.37 \\
China & 6071.2 & 6.03 & 10155.8 & 0.60 & 4.58 \\
Korea & 488.7 & 4.55 & 1065.7 & 0.46 & 10.09 \\
\hline
\end{tabular}

Source: IEA (2009).

According to the National Institute of Meteorological Research (NIMR) of Korea, the average temperature of the six biggest cities increased by $1.7^{\circ} \mathrm{C}$ between 1912 and 2008 , which is higher (even after taking urbanization effects into account) than the global average of $0.71-0.77^{\circ} \mathrm{C}$. NIMR also reported that, under the scenario of $720 \mathrm{ppm}$ in 2050 , the average temperature at the end of the twenty-first century will be $4^{\circ} \mathrm{C}$ higher than it was at the end of the twentieth century, and that the volume and volatility of precipitation would increase critically (NIMR 2009).

The need for participation in the international mitigation framework is also increasing. Under the UNFCCC, Korea is not considered a developed country, is not in Annex I (the original list of 37 industrialized countries and economies in transition), and therefore is not responsible for fulfilling the GHG emission reduction target to which Annex I countries are committed. However, taking the size of the Korean economy and its GHG emissions into account (see Table 1.1), it is inevitable for Korea to take some mitigation actions, although such actions could be different from those taken by the more developed countries.

In addition, an increasingly growing market for related industries highlights the need for active measures. Although there could be a debate on whether green technologies and green markets actually stimulate economic growth, the Korean government at least, facing a decline in the potential growth of the economy, seems to view them as a "new engine of growth." 
Various questions about coping with climate change, at both the global and the individual country levels, still remain. The most critical question is whether it is worthwhile to pursue climate change mitigation, if various uncertainties are considered. The answer to this question may be simple at the global level, but at the country level it could be quite complicated, owing to strategic considerations and political problems. If the answer is positive, more or less, the next question might be what is the best policy, or the best set of policies, to reduce GHG. Even though people may think that they know the best policy, how to implement it is a different issue, given political and other constraints. Thus, the question of constraints against forming an efficient mitigation framework would follow.

This book is arranged to answer these questions, both from the global perspective and from the standpoint of Korea. The authors do not pursue comprehensive answers for them, nor do they cover all relevant issues. Rather, the book attempts to address some critical issues, and each author presents a careful analysis of one such issue. These analyses provide at least some pieces of the puzzle as a contribution toward a more comprehensive picture.

The first half of the book examines issues from general and global perspectives, focusing on the costs and benefits of climate change mitigation (Chapter 2), the experience of mitigation policy in Europe (Chapter 3), energy policy for mitigation (Chapter 4), political economy in response to climate change (Chapter 5), and potential conflict between mitigation policy and the free trade framework (Chapter 6). The remaining chapters examine problems from the viewpoint of Korea, covering energy dependency and terms of trade (Chapter 7), energy policy (Chapter 8), and the GHG reduction policy of Korea (Chapter 9). We present an overview of each chapter here.

\section{BENEFITS AND COSTS OF MITIGATION}

Chapter 2 by Stephen Howes is motivated by the argument that the mitigation cost could be much larger than expected and thus could overwhelm the benefits by holding back economic growth. The main question that the author raises is whether the estimates of the mitigation costs in standard modeling exercises are underestimated, but his analysis provides broader outlines for the benefits and the costs of mitigation.

The estimates of global mitigation costs surveyed by the chapter range from 1 percent to 4 percent of global output in 2050, depending mainly on the modeling method and the stabilization target of the 
atmospheric concentration of GHG. The costs in this range are modest, corresponding to $0.02-0.10$ percentage point of annual average growth decline, or 4 to 17 months of growth delay. The author argues that these estimates are certainly sufficient to justify even a stringent mitigation target. His next question is therefore whether these estimates are reliable.

Howes examines several factors that potentially cause underestimation of the mitigation costs. He first notes that the cost of mitigation might be overestimated, as it stimulates growth through the first-mover advantage or investment and innovation. However, the gain is very uncertain, and industrial policies to pursue the first-mover advantage could merely add further costs. Second, transitional and distributional costs of mitigation would increase the political costs. This may raise the need for structural adjustment programs to accompany mitigation policy. But it does not lead to an underestimation of costs nor to a reduction in the need for mitigation. Third, incomplete participation in the global mitigation framework may increase the overall cost, owing to the limitations of the emissions trading systems, and will reduce the global environmental benefit as a result of "carbon leakage." The effect on the domestic cost of mitigation is ambiguous, however, since it depends on feedback from global mitigation to the domestic economy. The actual problem arising from incomplete participation is that it discourages mitigation efforts by participating countries.

The most critical causes of the underestimation of the costs, the author argues, are poor policies and differences between the costs at global and national levels. Recent experience shows that policymakers may choose inefficient policy options. The additional costs from policy errors should be a cause for alarm, even after taking into consideration the first-mover advantage and multiple market failures inherent in climate change mitigation. The author also emphasizes that decisions to mitigate are made at the national level. In the globally efficient mitigation framework, the mitigation costs vary across countries, owing mainly to the differences in current emission intensities. The cost is mostly higher in developing countries, but it is unlikely that those countries can achieve GHG reductions without appropriate compensatory transfers.

Howes concludes that the national costs of mitigation may well lie above the estimated range in standard modeling exercises. Still, he argues that these factors do not reduce the need for the mitigation, while they could discourage the efforts for it. Rather, what is needed is to reduce the cost and to enhance the environmental return, by designing efficient policies and by assisting developing countries with transfers. 


\section{THE DESIGN OF MITIGATION POLICY}

What does an efficient mitigation policy look like? Under the Kyoto protocol, a flexible mechanism composed of an emissions trading scheme (ETS), joint implementation (JI), and a clean development mechanism $(\mathrm{CDM})$ has been proposed as a cost-effective means of mitigation. In the mechanism, ETS is the main policy instrument, in that it is directly connected to the emissions reduction target. Up to now, only the European Union has operated an ETS, and its experience provides valuable lessons for the design of efficient mitigation policies by other countries. Chapter 3 by Jos Sijm reviews and evaluates the pilot phase (2005-07) of the EU ETS.

Sijm summarizes major features of the EU ETS from the pilot phase to the second trading period (2008-12). He discusses its cap-and-trade system, unrestricted intraperiod banking and borrowing, the interperiod ban on banking, limited participation in specific sectors, free allocation of emissions allowances, linking JI and CDM credits to the EU ETS, and the operation of the EU ETS registry system. He also surveys a number of studies about the effect of the scheme on emissions reduction, economic growth, industrial competitiveness, the development of a trading market, excessive allocation, and carbon leakage.

The pilot period of the EU ETS revealed several problems resulting from its allocation system, contrary to the theoretical prediction that the cap-and-trade system is capable of achieving cost efficiency, regardless of the allowance allocation method. The decentralized structure of the decisionmaking with almost all free allocation, in addition to relatively short allocation and trading periods, led to inefficient allocation of the emissions reduction target between the ETS and the non-ETS sectors, a race to the bottom, distortion of equity and competition, windfall profits, distortion of incentives for investments in emissions facilities, rent-seeking behavior, and growing uncertainty. Even so, the author argues that, despite a certain degree of excessive allocation during this period, GHG indeed appears to have been reduced. In addition, contrary to arguments that the system could hinder economic growth, degrade the competitiveness of several industries, and trigger carbon leakage, there has been no evidence to support these concerns. Furthermore, despite high price volatility in this period, the emissions trading market grew and expanded remarkably, succeeded in the establishment of the market infrastructure, and encouraged the development of the JI and CDM market.

Based on the lessons and experience from the first phase, the EU ETS is expected to seek institutional improvements after 2012, such as stricter and unified allowance allocation, integrated regulations on allocation, 
expansion of auction allocation, and extension of coverage and trading periods. Sijm concludes that, despite its defects, the initial phase of the EU ETS can be assessed as successful, in that it laid a foundation for subsequent institutional improvements. More importantly, it established a cultural change that made this new institution more acceptable, and it internalized the carbon price into economic decisionmaking.

The energy sector, owing mainly to its large share of GHG emissions, is of key importance in fulfilling the reduction target. In addition, it has policy goals other than mitigation (energy security being a notable one) and has a distinctive industrial and capital structure. For these reasons, special attention is given to the energy sector in designing a mitigation policy. Do we need a separate energy policy for mitigation in addition to the market based emissions policy such as the ETS? If so, what kinds of policy measures are needed? Richard Bradley addresses this issue in Chapter 4.

Chapter 4 begins with the examination of the proposed emissions reduction target. The goal of stabilizing the GHG concentration at $450 \mathrm{ppm}$ implies that net GHG emissions should peak and start to decline before 2020. This requires a radical change in the current energy infrastructure, including everything related to energy consumption. Considering, however, the lifetime of the capital composing the current energy infrastructure, it may not be easy for investors to expect a rapid transformation of the current capital structure.

Bradley argues that, recognizing such difficulties, it is more important to map out practical policies that contain an incentive system to drive longterm change, while setting the minimum cost as a target at the present. He suggests three elements to consider for planning such practical policies. First, it is necessary to focus on an energy efficiency policy, considering its cost merit and its immediate impact on final energy consumption. Second, the focus of the international discussion as to emissions control needs to be on major emitters and emissions sources, which is transitory in nature. For the present, confining the scope of the emissions control group to major emitters simplifies pending problems, thereby contributing to the process of reaching a global agreement, and also works effectively in terms of environmental protection. Furthermore, considering the huge share of electricity generation in the GHG emissions, it may also be possible to confine the emissions control sector to electricity generation. Lastly, without the development of new technology, it will be impossible to reach the stabilization target of $450 \mathrm{ppm}$. This highlights the need for efforts to increase research, development, and demonstration (RD\&D) in the public sector, which has been stagnant since the early 1990s. In this regard, intergovernment cooperation at the early R\&D stage (before the market competition) 
should be fully recognized, since it could help save resources and alleviate problems of intellectual property rights that could hinder the worldwide proliferation of a new technology.

\section{CONSTRAINTS AGAINST EFFICIENT MITIGATION POLICY}

Many factors are involved in climate change and its mitigation, and some of them could actually affect the design of mitigation policies. A policy that is efficient in the mitigation policy framework could conflict with other rules in the economy. More importantly, conflicts of interest among stakeholders and resulting politics could be hurdles to the design of efficient and equitable policies, as already noted in Chapter 2. Two chapters discuss some of the factors constraining policy design.

In Chapter 5, Lawrence Rothenberg reviews the political economy of climate change at both the international and the national levels. As is well known, the principle of policy solutions for climate change is to make the producers of GHG pay for the costs of their actions. Besides this straightforward principle, there have been so far a number of efforts searching for global collective action and advances in green technologies, providing reasons to be optimistic about our ability to deal with this problem effectively. Rothenberg emphasizes, however, that formulating an effective global solution and reflecting it back to domestic policies for implementation is not an easy task in reality. As a result, the atmospheric concentration of GHG continues to rise at an alarming rate.

Rothenberg addresses some key factors related to the political economy of climate change. First, the nature of "climate" or "climate change mitigation" as public goods (in particular, nonexclusion) creates conditions that make it difficult to produce incentives for participation, either by a state or by an individual economic player, in sharing the burden instead of pursuing a "free ride" strategy. Second, advanced economies and developing countries are placed in different positions regarding potential damages from climate change and the domestic demand for a solution to them. To draw developing countries toward international cooperation for climate change mitigation requires wealth transfers from advanced economies, of the sort that China has been advocating. But it is very difficult to expect political leaders of advanced economies to adopt and carry out such policies in their own countries. Their political life depends more on economic growth than on environment. Meanwhile, implementing policies for climate change mitigation, as a way to avoid such a situation, would often cause problems of time consistency and credibility. 
Rothenberg suggests that, in order to overcome these political-economic problems, it is necessary for the citizens to be convinced that climate change is real and that climate change mitigation is of considerable personal importance. In addition, political leaders should reflect any international agreement, such as a post-Kyoto protocol, in their domestic policies in a time-consistent manner. Finally, it is essential for the international community to establish an efficient cooperation and monitoring system.

ZhongXiang Zhang in Chapter 6 considers the relationship between mitigation policy and free trade rules, including the potential conflicts and synergies between them. In the current international cooperation framework, the regulation of GHG emissions varies across countries. This disparity is expected to continue for the time being, and it could result in carbon leakage owing to differences in production costs. Furthermore, political pressure would likely be exerted by industries subject to the regulations, because of worries about weakened industrial competitiveness.

Several measures to deal with the disparity have been proposed, and one of them is a border adjustment. In the United States, border adjustment measures in the form of emissions allowance requirements (EAR) are included under the proposed cap-and-trade regime. The author argues that these are the most concrete, unilateral trade measures for leveling the carbon playing field. Under EAR, importers are required to acquire and surrender emissions allowances for goods from countries that have not taken climate actions. The question raised is whether such measures could disturb the world trade order and trigger a trade war.

Zhang focuses on the legality of unilateral EAR under World Trade Organization (WTO) rules. He views border adjustment measures as essential, if regulations on GHG emissions are to be adopted in U.S. legislation. He argues, however, that a conflict between the trade and mitigation regimes could harm both regimes. Therefore, in designing such measures, the United States needs to scrutinize potential conflicts with WTO rules carefully, to make the U.S. legislation comply with the rules. He also suggests that the United States needs to explore cooperative sectoral approaches at an international level.

In addition, the author provides suggestions both for the United States and for its developing-country trade partners. On the U.S. side, for a successful WTO defense of the border adjustment provision, there should be a period of good faith efforts, to reach agreements with the countries concerned, before imposing such trade measures. Second, alternative options, with similar functions but less inconsistent with WTO provisions, should be considered. Finally, submissions by importers of alternative but equivalent emissions reduction units should be allowed. On the side of developing countries targeted by the measures, they should utilize the 
forums provided under the UNFCCC and Kyoto protocol to effectively deal with the measures to their advantage.

\section{RESPONSE OF KOREA TO CLIMATE CHANGE}

The final three chapters consider the issues of climate change and mitigation from the standpoint of Korea. The discussion about climate change began in earnest in Korea after the government announced its Green Growth National Strategy. Many policy options have been reviewed under the framework of the strategy, and some of them have already been implemented. There are, however, many remaining challenges. Some people still raise the question of why Korea should take active mitigation action, in a situation where Korea does not belong to the developed country group in the UNFCCC and where the future of international negotiations is uncertain. In terms of policy design, there are concerns whether market based policy tools adopted in developed countries would work properly in Korea.

In Chapter 7, Chin Hee Hahn and Sung-Hyun Ryu approach the need for the green growth strategy from a new angle: an economic viewpoint rather than an environmental one. Their attention is on the decline in terms of trade in Korea since the mid-1990s. They examine the causes of the decline using the decomposition method and regression analyses.

Their decomposition exercise finds that Korea's terms of trade have declined mainly owing to the goods price effect resulting from the rise of oil prices relative to prices of manufactured products. This phenomenon is commonly observed in many countries since the mid-1990s. In addition, their regression results also suggest that China's trade expansion contributed to the decline by raising the prices of oil and raw materials, while lowering the prices of manufactured products.

The empirical findings in this chapter provide some support for the green growth strategy. Korea is well known for its highly energydependent economic structure. Most of its energy, moreover, is imported. Taking this into consideration, the findings of the chapter imply that Korea's terms-of-trade decline might persist if economic growth continues in developing countries, especially China, and if Korea clings to its current economic structure. Thus, Korea needs a policy framework to lower its energy dependency, to reduce the external dependency of the economy, and to differentiate its export products from those of China. Innovative policies under the green growth strategy may therefore bring additional benefits by helping to change the economic structure.

Chapter 8 by Jin-Gyu Oh outlines and evaluates the policy framework 
in the initial stage of Korea's low-carbon green growth strategy, focusing on energy policy. He first examines the current state of affairs in terms of the nation's GHG inventory and energy-related $\mathrm{CO}_{2}$ emissions in detail. According to the data, the energy sector was by far the most significant emitter, accounting for 84 percent of total GHG emissions. Among emissions from fossil fuel combustion, the electricity generation sector (at 36.1 percent) and the industrial sector (at 31.7 percent) have the largest shares. He then presents the long-term outlook for energy consumption and $\mathrm{CO}_{2}$ emissions up to 2030, with projections of increases in both. Energy intensity (energy consumption per unit of GDP), carbon intensity $\left(\mathrm{CO}_{2}\right.$ emissions per unit of GDP), and $\mathrm{CO}_{2}$ emissions per unit of energy consumption are projected to decline, implying that energy efficiency and carbon efficiency are expected to improve. The results appear to come mainly from the assumption that the shares of energy-intensive sectors in manufacturing will decline.

The analysis in Chapter 8 shows that the trend in Korea is toward a lower carbon economy. But it is obvious that more efforts are necessary for the mitigation of climate change. Oh identifies two tasks for energy policy: the first is to lower carbon intensity by shifting the energy mix, and the second is to lower energy intensity by improving energy efficiency. The Korean government has already adopted, or is planning to adopt, policies for those purposes, including policies for developing green technology, energy efficiency programs, demand side management programs, promotion of energy efficient vehicles, and policies for nuclear power generation and renewable sources of energy.

The author points out, however, that there are many challenges to achieving these goals. First, in the shift of the energy mix, it will be necessary to gain public acceptance of nuclear power and technology development in the renewable energy sector. Second, current policies for the improvement of energy efficiency rely largely on regulatory measures rather than market based measures. In addition, current price regulation, which keeps prices lower than their costs, hinders efforts to promote more efficient energy consumption. The author recommends greater utilization of the price mechanism and reconsideration of energy pricing policies.

In Chapter 9, Kyoung-Soo Yoon and Min-Kyu Song discuss mitigation policy tools in Korea, in particular the ETS, beginning with the issue of policy mix. They argue that market based policies are superior, by inducing an efficient balance of input-substitution cost, reduction of abatement cost, and output-substitution cost. However, they also note that it may be inevitable, in the actual reduction policies, to combine multiple policy instruments, owing to multiple market failure factors and political constraints. But even in this case, it will be necessary to closely monitor the 
interaction between policy instruments, as a means of avoiding double regulation problems and also ensuring a comprehensive policy in order to prevent carbon leakage. As illustrated in Chapter 8 in detail, many policies are proposed for similar policy objectives in Korea. For this reason, designing an efficient set of policy instruments will be critical to minimize the mitigation cost.

The chapter then addresses a few issues about the design of the ETS in Korea. First, concerning the allocation of tradeable permits, the authors argue that auction allocation is superior in terms of allocative efficiency, macroeconomic efficiency, and equity. However, considering the compensation for the decline in corporate value and for the policy acceptability during the initial adoption period, a gradual increase of the portion of auctioning from mostly free allocation may be desirable. Second, special attention should be paid to the power sector in Korea, because of the high market concentration, the cost based pool system in the wholesale market, and price regulation for electricity. It is probable that ETS in the power sector will not work properly because the emissions cost will not be efficiently passed through to the consumer price, especially when the free permit allocation system is adopted. To avoid such a problem, the government might consider applying a carbon tax to the power sector, or adopting a pricing scheme that links the consumer price to the permit price.

The chapter then discusses the design of a permit trading market. Unless the Korean carbon market is connected directly to outside big markets such as the EU ETS, it is expected that the market will be very thin, especially in the initial period. Under these circumstances, the market should be designed for efficient price discovery and provided with risk management tools, to keep the volatility of prices low. Taking these factors into account, the authors emphasize that balances between transparency and anonymity and between the exchange and the over-the-counter markets should be pursued. They further recommend predictable reduction targets over time, active derivatives markets, and possible additions of a central clearing house (the central counter party or CCP system) and carbon central banking.

Climate change is a global, long-lasting phenomenon that the world must cope with in the twenty-first century. The authors in this book assert in common that responding to it is inevitable, but also acknowledge that there are many difficulties and large uncertainties. During the past two decades, many countries have made great strides toward the goal of mitigating climate change, but these were just the first steps in a long journey. Much more experience is needed in order to develop policies that are cost effective and acceptable, especially for developing countries and 
newly developed countries such as Korea. To do so and to design creative policies based on sound principles, valuable lessons can be drawn from the limited experiences already available. This book examines such lessons now emerging from recent experiments and raises key issues from the perspective of Korea, as one among many newly developed nations that will contribute to this global effort.

\section{REFERENCES}

International Energy Agency (IEA). 2009. $\mathrm{CO}_{2}$ Emissions from Fuel Combustion Highlights. Paris: International Energy Agency.

National Institute of Meteorological Research (NIMR). 2009. Understanding the Climate Change II: Climate Change in the Korean Peninsula at the Present and in the Future. Seoul: National Institute of Meteorological Research. In Korean.

Organisation for Economic Co-operation and Development (OECD). 2009. Climate Change Mitigation: Policies and Options for Global Action beyond 2012. Paris: Organisation for Economic Co-operation and Development.

Rodrik, Dani. 2005. "Growth Strategies." In Handbook of Economic Growth, edited by Philippe Aghion and Steven N. Durlauf, pp. 967-1014. Amsterdam: North Holland.

Stern, Nicholas. 2007. The Economics of Climate Change: The Stern Review. Cambridge and New York: Cambridge University Press.

World Bank. 2008. The Growth Report: Strategies for Sustained Growth and Inclusive Development. Commission on Growth and Development. Washington: World Bank. 